\title{
Nonlinear Digital-Based Control of Nonlinear System
}

\author{
Amirzubir Sahamijoo ${ }^{1}$, Farzin Piltan ${ }^{1,2}$, , Ali Taghizadegan ${ }^{1}$, Rouhollah \\ Bahrami $^{1,3}$, Hossein Rashidi Bod ${ }^{1}$, Somayeh Jowkar ${ }^{1,4}$ and Nasri. B Sulaiman ${ }^{1,5}$ \\ ${ }^{1}$ Intelligent System and Robotic Lab, Iranian Institute of Advanced Science and \\ Technology (IRAN SSP), Shiraz/Iran \\ ${ }^{2}$ Embedded System Lab, Department of Electrical, Electronic and Computer \\ Engineering, University of Ulsan, Ulsan, South Korea \\ ${ }^{3}$ Department of Electrical-Electronic Engineering, Islamic Azad University, Iran \\ ${ }^{4}$ Department of Information Technology, Faculty of Computer Engineering, \\ Ateneo De Manila University, Manila/Philippines \\ ${ }^{5}$ Department of Electrical Engineering, Faculty of Engineering, University Putra \\ Malaysia, Malaysia \\ Corresponding author \\ Farzin Piltan, Department of Electrical, Electronics and Computer Engineering, \\ University of Ulsan, Ulsan, South Korea \\ Email: piltan_f@iranssp.org,www.iranssp.org/english
}

\begin{abstract}
In this research paper, nonlinear FPGA-based feedback linearization position controller is recommended for serial links robot manipulator. Robot manipulators are multi-input multi-output (MIMO), nonlinear, time variant, uncertain dynamic systems and are developed either to replace human work in many fields such as in industrial or in the manufacturing. Complexities of the tasks caused to design mechanical architectures, nonlinear behavior, uncertain dynamic formulation and strong coupling effects between joints therefore, control of these systems is extremely complicated. To design robust and stable methodology robust functional-based feedback linearization technique is recommended. Functional based feedback linearization is a combined nonlinear, stable, robust and reliable controller. Pure feedback linearization method has three important drawbacks: stability, uncertainty and processing time. To improve the system's stability, robustness and uncertainty, functional based method is recommended. The challenge of system's processing time as well high frequency response is solved by design of FPGA based high frequency functional based method. The simulation results show that the proposed method works well in certain and uncertain conditions. Beside improve the stability, robustness and time response this control technique improve the sensitivity as well reduce the rate of energy consumption.
\end{abstract}

Keywords: surgical robots, four degrees of freedom, functional-based feedback linearization method, FPGA

\section{Introduction}

A robot is a machine that can be programmed to do a range of tasks. One of the most important types of robot which used in industry and also medical applications is robot manipulator. Because of the robot manipulator is MIMO, nonlinear and time variant system so control of robot manipulator is one of the complicated subjects for control and mechanical researchers [1]. To improve the robot manipulator's performance nonlinear control methodology is recommended. 
To reduce coupling effects beside the above challenges nonlinear feedback linearization controller is recommended. Feedback linear controller is one of the effective nonlinear controllers for certain situations. To solve the challenge of coupling effect without using many gears, feedback linearization controller is introduced. However this control technique has many advantages but it has three important drawbacks: 1) stability and robustness, 2) uncertainty challenge, and 3) time of system's response [2].

Mathematical functional based method; improve the rate of variations especially in uncertain condition to improve the controller's robustness. Mathematical function divided into different categories such as saturation function, switching function and sigmoid function. To improve the robustness switching mode function is recommended to improve the feedback linearization method. However this method improve the robustness and uncertainty but it has a limitation in output timing response which to solve this challenge design FPGA based controller is recommended. The aim of the design of FPGA based control scheme is to reduce the time of processing and have small size device. FPGA based system is used in many applications such as industrial automation, robotic surgery, and fault prognosis [3-6].

This paper is organized as follows; Section 2, is served as the robot manipulator dynamic formulation. Part 3, introduces and describes the robust functional FPGA based feedback linearization controller for robot manipulator. Part 4, focuses on the robust functional based feedback linearization controller in presence of uncertainty and robust functional FPGA based feedback linearization controller, and in the final section conclusion is presented.

\section{Theorem}

Robot Manipulator Dynamic Formulation: In control point of view robot manipulator has two main parts, kinematics and dynamics. The dynamic formulation of robot manipulator used to describe the behavior of system. The dynamic equation of a multi degrees of freedom (DOF) robot manipulator is [1-2]:

$$
\boldsymbol{\tau}=\boldsymbol{M}(\boldsymbol{q}) \ddot{q}+\boldsymbol{B}(\boldsymbol{q})[\ddot{q} \ddot{q}]+\boldsymbol{C}(\boldsymbol{q})[\ddot{q}]^{2}+\boldsymbol{G}(\boldsymbol{q})
$$

Where $\tau$ is $n \times 1$ vector of actuation torque/force, $\mathrm{M}$ (q) is $n \times n$ symmetric and positive define inertia matrix, $B(q)$ is matrix of coriolis torques, $C(q)$ is matrix of centrifugal torque, $\mathrm{G}(\mathrm{q})$ is vector of gravity, $[\dot{q} \dot{q}]$ is vector of joint velocity that it can give by: $\left[\dot{q}_{1}, \dot{q}_{2}, \dot{q}_{1}, \dot{q}_{3}, \ldots, \dot{q}_{1}, \dot{q}_{n}, \dot{q}_{2}, \dot{q}_{3}, \ldots . . .\right]^{T}$, and $[\dot{q}]^{2}$ is vector, that it can given by: $\left[\dot{q}_{1}^{2}, \dot{q}_{2}{ }^{2}, \dot{q}_{3}{ }^{2}, \ldots . .\right]^{T}$. Figure 1 shows an open loop input-output response. 

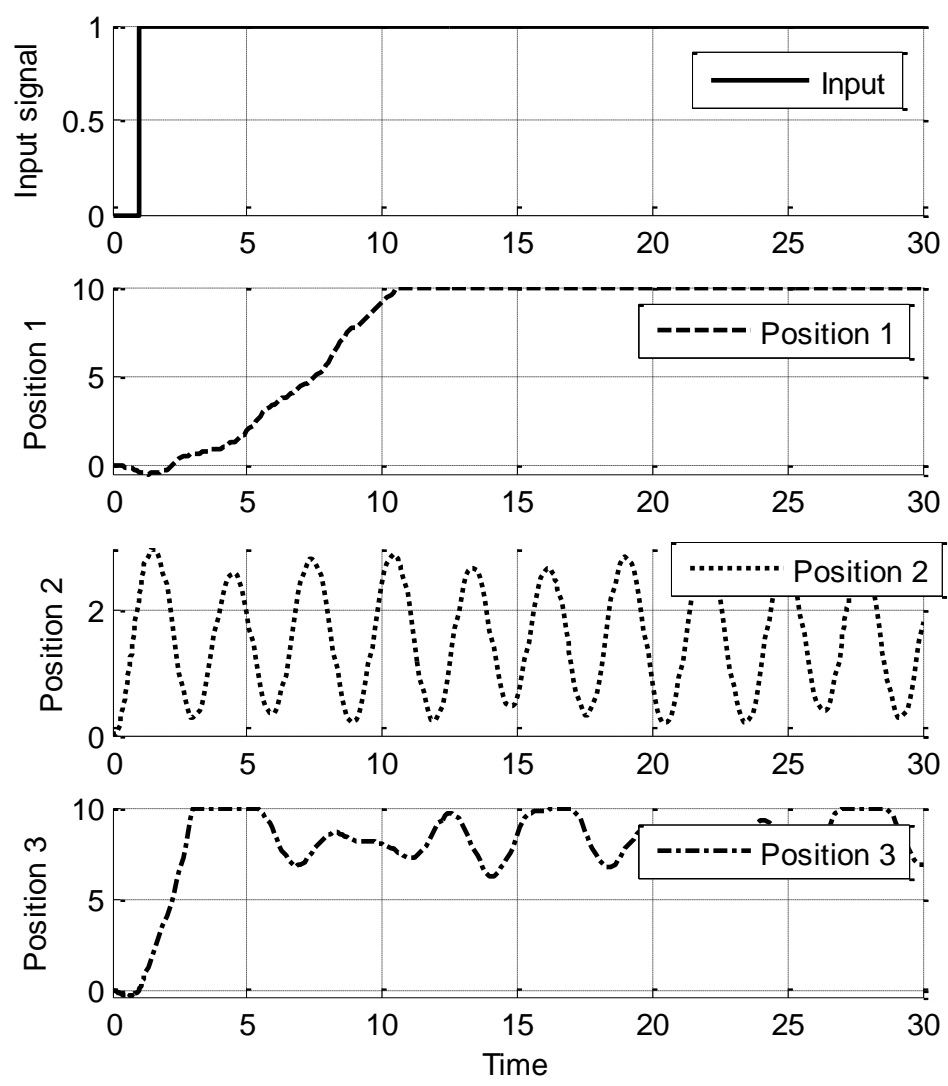

Figure 1. Open Loop Input/Output Data Set

\section{Methodology}

Pure feedback linearization method is a nonlinear and reliable controller. This controller works in many applications but it has two main issues limiting: robust, stability and uncertainty limitation and output system's response. Defines the tracking error as:

$$
e(t)=q_{d}(t)-q_{a}(t)
$$

Where $\mathrm{e}(\mathrm{t})$ is error of the plant, $q_{d}(t)$ is desired input variable, $q_{a}(t)$ is actual displacement. The linear type state space equation is:

$$
\dot{x}=\left[\begin{array}{ll}
0 & I \\
0 & 0
\end{array}\right] x+\left[\begin{array}{l}
0 \\
I
\end{array}\right] U
$$

In this equation $\mathrm{U}$ is the nonlinear term and is

$$
U=-M^{-1}(q) \cdot N(q, \dot{q})+M^{-1}(q) \cdot \tau
$$

The Brunousky canonical form

$$
\begin{gathered}
\frac{d}{d t}\left[\begin{array}{l}
e \\
\dot{e}
\end{array}\right]=\left[\begin{array}{ll}
0 & I \\
0 & 0
\end{array}\right] \cdot\left[\begin{array}{l}
e \\
\dot{e}
\end{array}\right]+\left[\begin{array}{l}
0 \\
I
\end{array}\right] U \\
U=\ddot{q}_{d}+M^{-1}(q) \cdot\{N(q \cdot \vec{q})-\tau\}
\end{gathered}
$$

Based on controller dynamic formulation:

$$
\tau=\boldsymbol{M}(\boldsymbol{q})\left(\ddot{q_{d}}-U\right)+\boldsymbol{N}(\ddot{q}, q)
$$

To have the better performance, design the optimal $\boldsymbol{U}$ play an important role. To improve the robustness and stability mathematical functional based method is applied to conventional feedback linearization method. 


$$
\tau_{\text {New method }}=K \times f_{\text {switching }}\left(\ddot{q}_{d}-U\right)+N(\dot{q}, q)
$$

To have the stability and minimum error, $\boldsymbol{U}$ should be near to the zero.

$$
\begin{gathered}
\frac{1}{2} \frac{d}{d t} U^{2}(x, t) \leq-\zeta|U(x, t)| \\
U>0 \rightarrow U(t) \leq-\zeta \rightarrow \int_{t=0}^{t=t_{\text {reach }}} U(t) \leq-\int_{t=0}^{t=t_{\text {reach }}} \eta \rightarrow U\left(t_{\text {reach }}\right)-U(0) \leq-\zeta\left(t_{\text {reach }}-0\right) \\
0-U(0) \leq-\eta\left(t_{\text {reach }}\right) \rightarrow t_{\text {reach }} \leq \frac{U(0)}{\zeta} \\
U<0 \rightarrow 0-U(0) \leq-\eta\left(t_{\text {reach }}\right) \rightarrow U(0) \leq-\zeta\left(t_{\text {reach }}\right) \rightarrow t_{\text {reach }} \leq \frac{\| U(0) \mid}{\eta} \\
\text { if } U_{t_{\text {reach }}}=U(0) \rightarrow \operatorname{error}\left(x-x_{d}\right)=0
\end{gathered}
$$

Based on $(12,13)$ the stability and robustness improve in new methodology compare with pure feedback linearization method. FPGA based new methodology controller has the following subparts:

- Design $\boldsymbol{f}_{\text {switching }}$

- Design secondary derivation of joint

- Design $\mathbf{U}$

- Design nonlinearity term $\boldsymbol{N}(\boldsymbol{q}, \vec{q})$

To design FPGA based switching function we have:

$$
f(\text { switching })= \begin{cases}1 & U>0 \\ -1 & U<0 \\ 0 & U=0\end{cases}
$$

Figure 2 shows the block diagram of FPGA based switching function methodology.

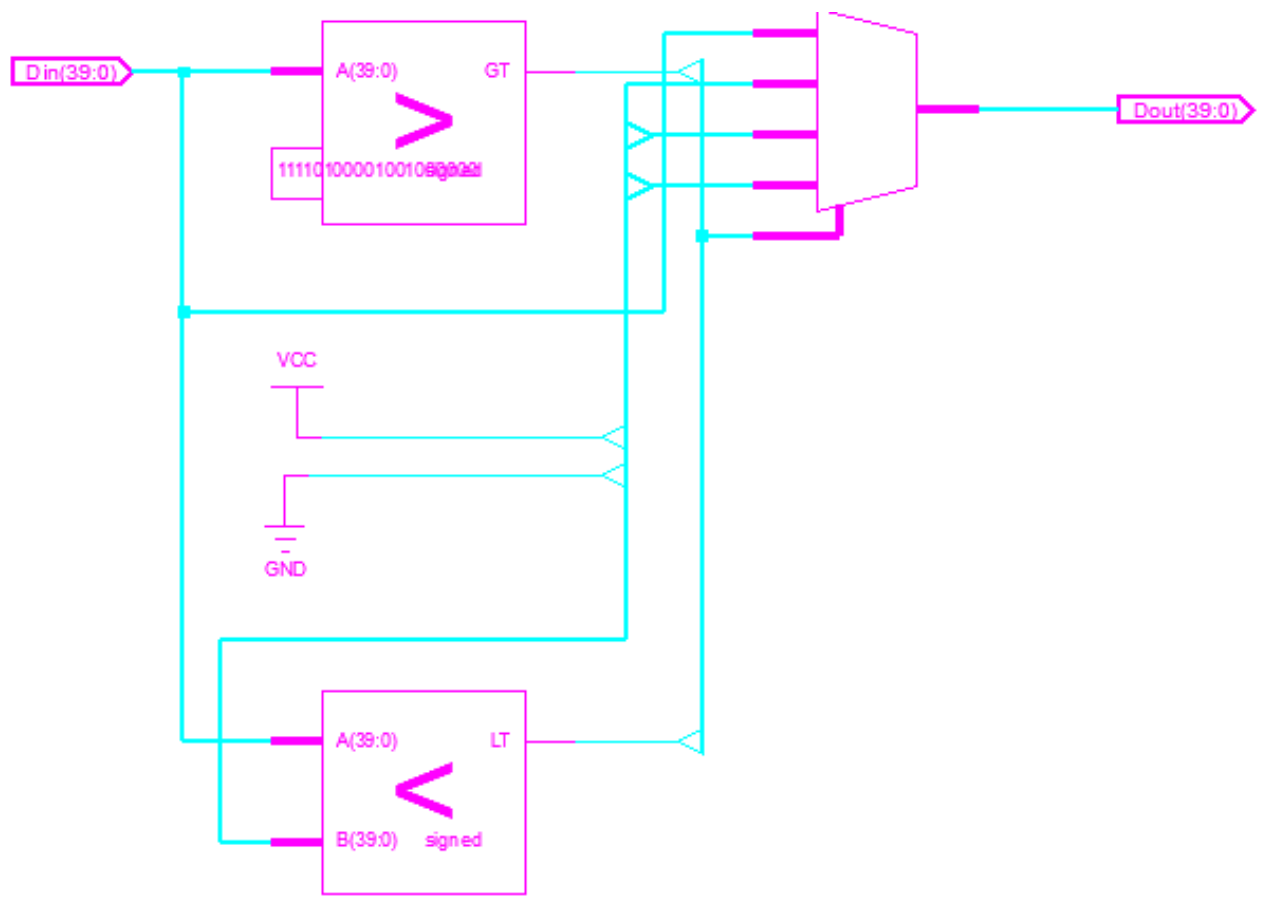

Figure 2. FPGA-Based Switching Function

To design second-type derivative function we have

$$
d(e)=\frac{\operatorname{Din}(t)-\operatorname{Din}(t-1)}{\Delta t} \rightarrow \partial e=(\operatorname{Din}(k+1)-\operatorname{Din}(k)) \times \text { sample time }
$$

Figure 3 shows the derivative part of control system. 


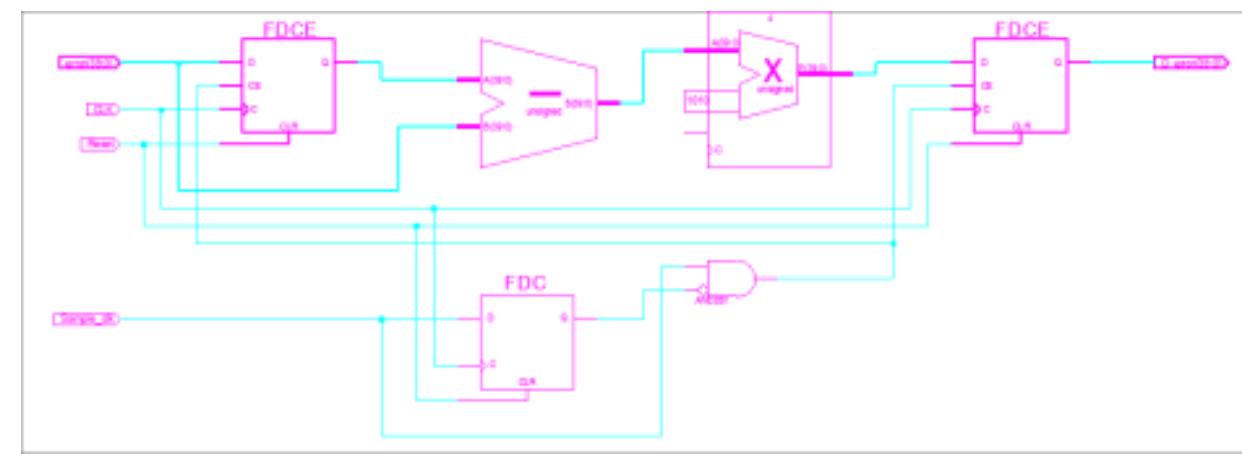

Figure 3. Derivative Part of Control System

To design $\mathbf{U}$, based on system information and configuration linear or nonlinear function is introduced. In this research linear mode PD control technique is recommended. To design PD controller derivative part control method applied to PD control technique.

One of the main challenges to design FPGA based new method is design nonlinearity term. To design this term, memory based rule method is recommended. Figure 4 shows the block diagram of FPGA based nonlinear system design.

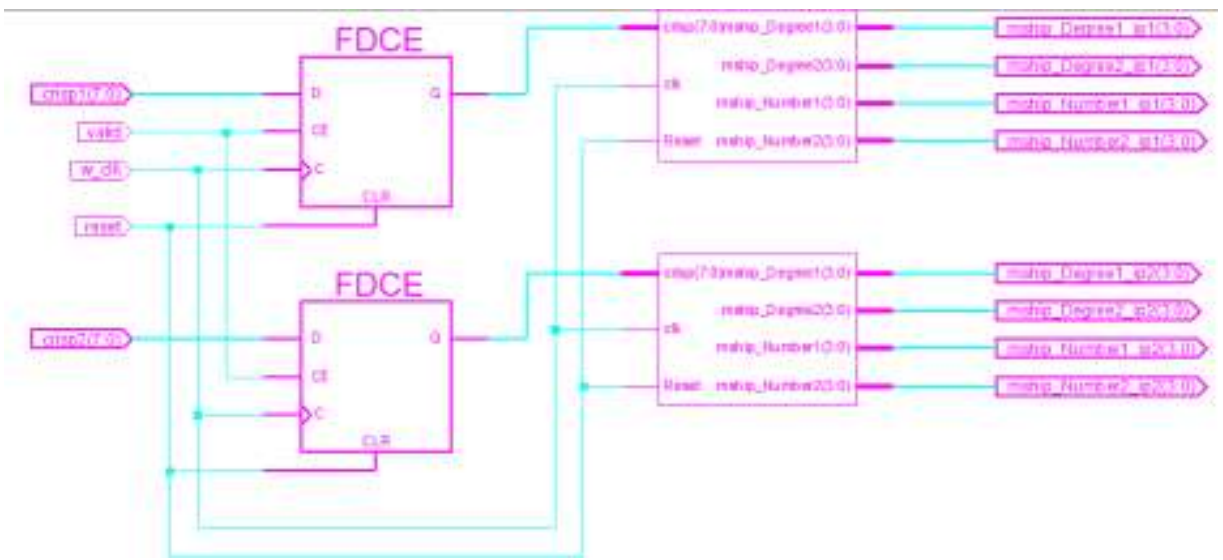

Figure 4. Design Memory Based FPGA Based Nonlinear Term

\section{Results and Discussion}

In the first part of result and discussion feedback linearization method and new method are comparing. Figure 5 shows the output trajectory following in presence of uncertainty for feedback linearization method and functional based feedback linearization method. 


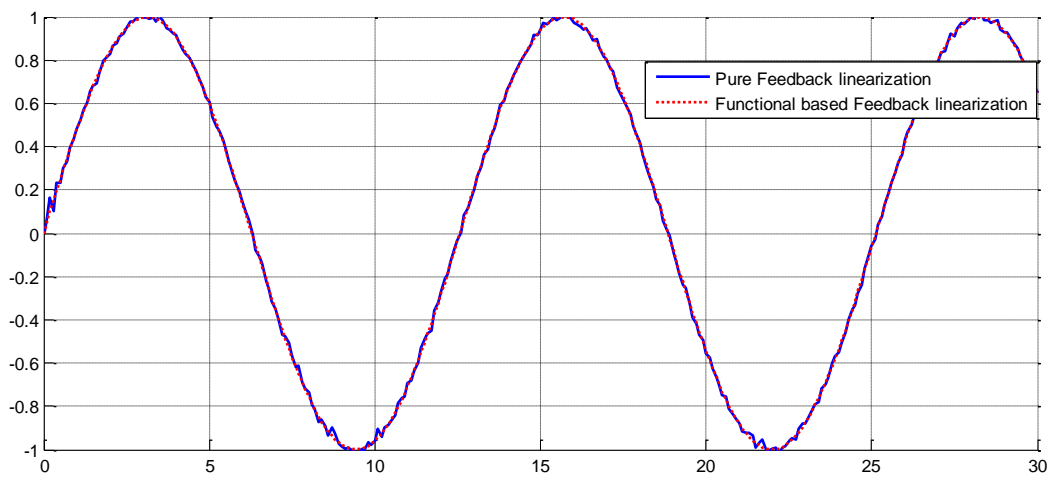

Figure 5. Pure Feedback Linearization VS New Method

According to Figure 5, the pure feedback linearization method has fluctuation in presence of uncertainty but new method is more robust. The maximum desired input frequency in FPGA functional based feedback linearization controller is $64 \mathrm{MHz}$ but the actual frequency system's output is about $33 \mathrm{MHz}$. The timing report shows that the delay response in $\boldsymbol{f}_{\text {switching }}$ is about 4.4 nanoseconds, in derivative part design the delay response is about 15.7 nanoseconds, in linear PD control technique the delay time is 19.1 nanoseconds and finally in nonlinearity memory based design the delay time report is about 30.286 nanoseconds. Figure 6 shows the transient error in functional FPGA based feedback linearization controller in robot manipulator.

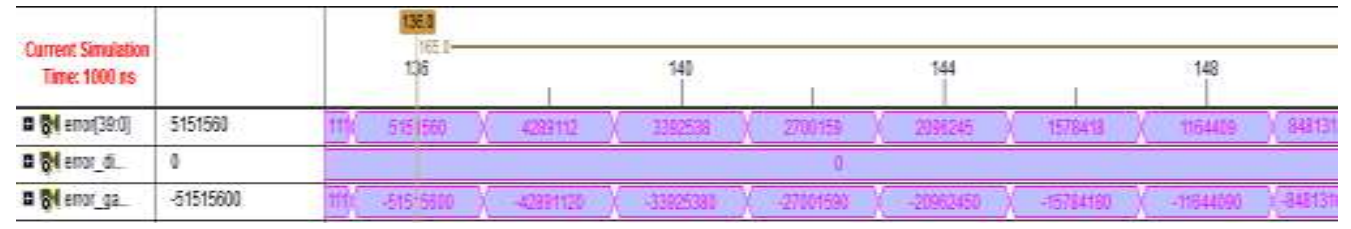

Figure 6. Transient Error Response

According to the Figure 6, the rate of error reduction is extremely fast. The error rate at 136 nanoseconds is about 5.15, in 140 nanoseconds is about 3.3 and in 148 nanoseconds the rate of error is 1.16. Based on the above Figure the rate of error reduces $75 \%$ in 12 nanoseconds. Figure 7 shows the rate of between 160 to 172 nanoseconds.

\begin{tabular}{|c|c|c|c|c|c|c|c|c|}
\hline $\begin{array}{l}\text { Currant Simulabon } \\
\text { Tene } 1000 \text { ss }\end{array}$ & \multirow[b]{2}{*}{5151560} & 100 & & 164 & \multicolumn{3}{|c|}{$16 t$} & 172 \\
\hline 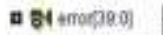 & & किसे & 1329 & ก17rii & जोना? & $x^{2}+2=$ & $\frac{1}{104}$ & $2 x^{2}$ \\
\hline a 54 orme al & 0 & \multicolumn{7}{|c|}{0} \\
\hline a 84 trmot_al & 41515000 & वाता & 12amm & grlom & GA45? & sentin & Jecตม & 20055 \\
\hline
\end{tabular}

Figure 7. Rate of Error ( $t=160-172$ Nanoseconds)

According to above Figure the rate of error reduce from 1.6 at $t=160$ nanoseconds to 0.24 at $\mathrm{t}=172$ nanoseconds. According to above Figures in presence of uncertainty functional FPGA based feedback linearization controller has no fluctuations.

\section{Conclusion}

In this paper, robust functional FPGA based feedback linearization controller is designed and applied to robot manipulator. According to the results functional based feedback linearization method is more robust than pure feedback linearization method in presence of uncertainty. The rate of output frequency in functional FPGA based feedback 
linearization controller is about $33 \mathrm{MHZ}$. The rate of steady state error in presence of uncertainty is less than 0.00006 at 208 nanoseconds.

\section{Acknowledgment}

This work was supported by the Iranian Institute of Advance Science and Technology Program of Iran under grant no. 2015-Persian Gulf-2.

Project Title: Research on Intelligent FPGA-Based Algorithm for Four Degrees of Freedom Joints

Iranian center of Advance Science and Technology (IRAN SSP) is one of the independent research centers specializing in research and training across of Control and Automation, Electrical and Electronic Engineering, and Mechatronics \& Robotics in Iran. At IRAN SSP research center, we are united and energized by one mission to discover and develop innovative engineering methodology that solve the most important challenges in field of advance science and technology. The IRAN SSP Center is instead to fill a long standing void in applied engineering by linking the training a development function one side and policy research on the other. This center divided into two main units:

- Education unit

- Research and Development unit

Please follow IRANSSP research and training group: http://iranssp.org/english/

\section{References}

[1] T. R. Kurfess, Robotics and automation handbook: CRC, 2005.

[2] B. Siciliano and O. Khatib, Springer handbook of robotics: Springer-Verlag New York Inc, 2008.

[3] Faraji, R., Rouholamini, A., Naji, H. R., Fadaeinedjad, R., \& Chavoshian, M. R. (2014). FPGA-based real time incremental conductance maximum power point tracking controller for photovoltaic systems. Power Electronics, IET,7(5), 1294-1304.

[4] X. Shao, D. Sun and J. K. Mills, "A new motion control hardware architecture with FPGA-based IC design for robotic manipulators," IEEE International Conference on Robotics and Automation, 2006, pp. 3520-3525.

[5] Faraji, R., Rouholamini, A., Naji, H. R., Fadaeinedjad, R., \& Chavoshian, M. R. (2014). FPGA-based real time incremental conductance maximum power point tracking controller for photovoltaic systems. Power Electronics, IET,7(5), 1294-1304.

[6] Ghosh, S., Barai, R. K., Bhattarcharya, S., Bhattacharyya, P., Rudra, S., Dutta, A., \& Pyne, R. (2013, January). An FPGA based implementation of a flexible digital PID controller for a motion control system. In Computer Communication and Informatics (ICCCI), 2013 International Conference on (pp. 1-6). IEEE.

\section{Authors}

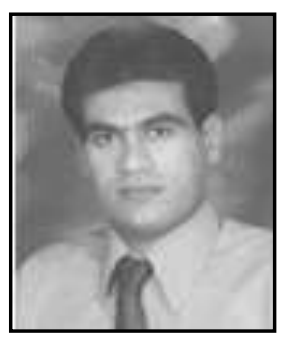

Amirzubir Sahamijoo, currently is senior research assistant at Institute of Advanced Science and Technology, Research Center, IRAN SSP. He is senior research assistant of team to Design Intelligent FPGA-Based Control Unit to Control of 4-DOF Medical Robot Manipulator since July, 2015 to now, research assistant of team (8 researchers) to design a Micro-electronic Based nonlinear controller for first order delay system since March, 2015 to now, research student (21 researchers) to design high precision and fast dynamic controller for multi-degrees of freedom actuator since 2014 to date, research student (9 researchers) to design Prevent the Risk of Lung Cancer Progression Based on Fuel Ratio Optimization since 2014 to date, and published 4 journal papers since 2014 to date. His current research interests are nonlinear 


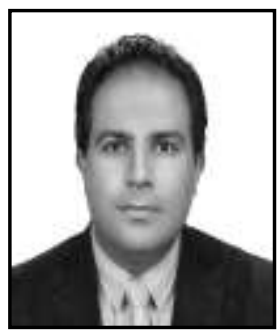

control, artificial control system, Microelectronic Device, Internal Combustion Engine, and HDL design.

Farzin Piltan, is an outstanding scientist in the field of Electronics and Control engineering with expertise in the areas of nonlinear systems, robotics, and microelectronic control. Currently, Mr. Piltan works as a researcher in Embedded system Laboratory, Department of Electrical, Electronics and Computer Engineering, University of Ulsan, South Korea as well is the Head of Mechatronics, Intelligent System, and Robotics Laboratory at the Iranian Institute of Advanced Science and Technology (IRAN SSP). Mr. Piltan led several high impact projects involving more than 150 researchers from countries around the world including Iran, Finland, Italy, Germany, South Korea, Australia, and the United States. Mr. Piltan has authored or co-authored more than 140 papers in academic journals, conference papers, and book chapters. His papers have been cited at least 3900 times by independent and dependent researchers from around the world including Iran, Algeria, Pakistan, India, China, Malaysia, Egypt, Columbia, Canada, United Kingdom, Turkey, Taiwan, Japan, South Korea, Italy, France, Thailand, Brazil and more. Moreover, Mr. Piltan has peer-reviewed at least 23 manuscripts for respected international journals in his field. Mr. Piltan will also serve as a technical committee member of the upcoming EECSI 2015 Conference in Indonesia. Mr. Piltan has served as an editorial board member or journal reviewer of several international journals in his field as follows: International Journal Of Control And Automation (IJCA), Australia, ISSN: 2005-4297, International Journal of Intelligent System and Applications (IJISA), Hong Kong, ISSN:2074-9058, IAES International Journal Of Robotics And Automation, Malaysia, ISSN:2089-4856, International Journal of Reconfigurable and Embedded Systems, Malaysia, ISSN:20894864.

Mr. Piltan has acquired a formidable repertoire of knowledge and skills and established himself as one of the leading young scientists in his field. Specifically, he has accrued expertise in the design and implementation of intelligent controls in nonlinear systems. Mr. Piltan has employed his remarkable expertise in these areas to make outstanding contributions as detailed follows:Nonlinear control for industrial robot manipulator (2010IRAN SSP), Intelligent Tuning The Rate Of Fuel Ratio In Internal Combustion Engine (2011-IRANSSP), Design High Precision and Fast Dynamic Controller For Multi-Degrees Of Freedom Actuator (2013-IRANSSP), Research on Full Digital Control for Nonlinear Systems (2011-IRANSSP), Micro-Electronic Based Intelligent Nonlinear Controller (2015-IRANSSP), Active Robot Controller for Dental Automation (2015-IRANSSP), Design a MicroElectronic Based Nonlinear Controller for First Order Delay System (2015-IRANSSP).

The above original accomplishments clearly demonstrate that Mr. Piltan has performed original research and that he has gained a distinguished reputation as an outstanding scientist in the field of electronics and control engineering. Mr. Piltan has a tremendous 


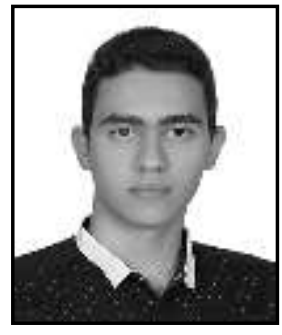

and unique set of skills, knowledge, and background for his current and future work. He possesses a rare combination of academic knowledge and practical skills that are highly valuable for his work. In 2011, he published 28 first-author papers, which constitute about $30 \%$ of papers published by the Department of Electrical and Electronic Engineering at University Putra Malaysia. Additionally, his 28 papers represent about $6.25 \%$ and $4.13 \%$ of all control and system papers published in Malaysia and Iran, respectively, in 2011.

Ali Taghizadegan, is currently studying as a student in the second grade of Shahid dastgheib's 1 high school and Research Student at Iranian Institute of Advanced Science and Technology, Research and Training Center, IRAN SSP. He is research student of team (6 researchers) to design Micro-electronic Based nonlinear controller for Four Degrees of Freedom Surgical Robot Manipulator since August 2015. His current research interests are nonlinear control, artificial control system, Microelectronic Device, and HDL design.

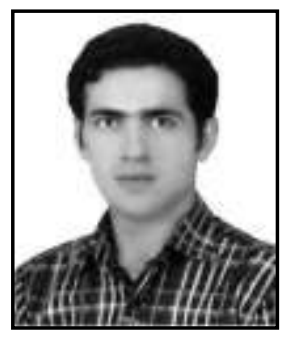

Rouhollah Bahrami, currently is research student at Institute of Advanced Science and Technology, Research Center, IRAN SSP. $\mathrm{He}$ is research student of team (6 researchers) to design Microelectronic Based nonlinear controller for Four Degrees of Freedom Surgical Robot Manipulator since August 2015. His current research interests are nonlinear control, artificial control system, Microelectronic Device, and HDL design.

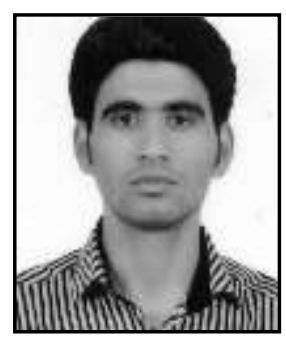

Hossein Rashidi Bod, currently is research student at Institute of Advanced Science and Technology, Research Center, IRAN SSP. He is research student of team (6 researchers) to design Micro-electronic Based nonlinear controller for Four Degrees of Freedom Surgical Robot Manipulator since August 2015. His current research interests are nonlinear control, artificial control system, Microelectronic Device, and HDL design.

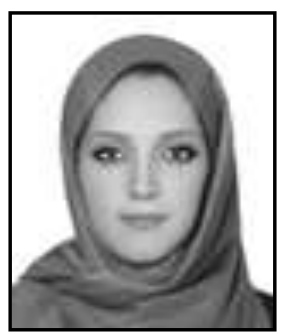

Somayeh Jowkar, currently is research assistant at Institute of Advanced Science and Technology, Research Center, IRAN SSP. She is research assistant of team to Design Intelligent FPGA-Based Control Unit to Control of 4-DOF Medical Robot Manipulator since July, 2015 to now, research student (21 researchers) to design high precision and fast dynamic controller for multi-degrees of freedom actuator since 2014 to date, and published 2 journal papers since 2014 to date. Her current research interests are nonlinear control, artificial control system, Microelectronic Device and HDL design.

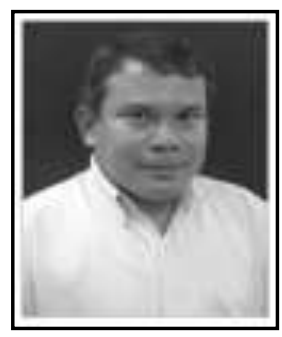

Nasri Sulaiman, advisor and supervisor of several high impact projects involving more than 150 researchers from countries around the world including Iran, Malaysia, Finland, Italy, Germany, South Korea, Australia, and the United States. Dr. Nasri Sulaiman has authored or co-authored more than 80 papers in academic journals, 
conference papers and book chapters. His papers have been cited at least 3000 times by independent and dependent researchers from around the world including Iran, Algeria, Pakistan, India, China, Malaysia, Egypt, Columbia, Canada, United Kingdom, Turkey, Taiwan, Japan, South Korea, Italy, France, Thailand, Brazil and more. Dr. Nasri Sulaiman has employed his remarkable expertise in these areas to make outstanding contributions as detailed below:

- Design of a reconfigurable Fast Fourier Transform (FFT) Processor using multi-objective Genetic Algorithms (2008UPM)

- Power consumption investigation in reconfigurable Fast Fourier Transform (FFT) processor (2010-UPM)

- Crest factor reduction And digital predistortion Implementation in Orthogonal frequency Division multiplexing (ofdm) systems (2011-UPM)

- High Performance Hardware Implementation of a MultiObjective Genetic Algorithm, (RUGS), Grant amount RM42,000.00, September (2012-UPM)

- Nonlinear control for industrial robot manipulator (2010-IRAN SSP)

- Intelligent Tuning The Rate Of Fuel Ratio In Internal Combustion Engine (2011-IRANSSP)

- Design High Precision and Fast Dynamic Controller For MultiDegrees Of Freedom Actuator (2013-IRANSSP)

- Research on Full Digital Control for Nonlinear Systems (2011IRANSSP)

- Micro-Electronic Based Intelligent Nonlinear Controller (2015IRANSSP)

- Active Robot Controller for Dental Automation (2015IRANSSP)

- Design a Micro-Electronic Based Nonlinear Controller for First Order Delay System (2015-IRANSSP) 